\title{
Una escena de traducción en América Latina: "Las dos orillas" de Carlos Fuentes
}

\author{
Ilse Logie \\ Universiteit Gent
}

In his short story "The two shores" the Mexican writer Carlos Fuentes (The Orange Tree, 1993) fictionalizes language contact. In this apocryphal rewriting of the chronicle of Bernal Diaz del Castillo, The True History of the Conquest of New Spain, the author puts translation on the centre stage by focusing on the ambiguous relations between the two top interpreters of Spanish conqueror Hernán Cortés: Jerónimo de Aguilar and La Malinche. Besides, translation is also the genetic source of the story since it is itself an adaptation of an existing chronicle. In Fuentes's version, Aguilar consciously distorts Cortés's words in order to reveal the conqueror's true intentions and to demonstrate his solidarity with the indigenous populations, the Aztecs and the Mayas. The story can be read as a reflection on the complex loyalties of translators and on language's colonizing potential. It reconsiders the function of translation, which is presented as performative speech act rather than as a purely reproductive form of transfer. According to Fuentes, translation is an activity that is caught in a double bind as it harbors a potential for disruption and betrayal as well as for subversion.

\section{Una reescritura apócrifa}

La novela breve "Las dos orillas" encabeza el volumen El naranjo (o los círculos del tiempo), ${ }^{2}$ que está conformado por cinco relatos históricos. El naranjo, que asegura la unidad del libro, aparece en los cinco textos como hilo conductor y símbolo del mestizaje, que constituye la antigua metáfora de la formación identitaria en América. ${ }^{3}$ Originario del sudeste de Asia, hoy en día se le considera emblema de la españolidad, con sus flores de azahar de color blanco muy perfumadas, pero antes de llegar a serlo, recorrió mucho mundo: fue domesticado en China, introducido en el Mediterráneo por los árabes y, desde allí, trasladado a América Latina donde actualmente da una fruta ligeramente diferente: una naranja más grande, menos colorada y más agria, casi como una toronja (48). Y al evocar el proceso de replantar y transplantar las semillas en nuevas tierras, el naranjo también funciona como una de las imágenes orgánicas más utilizadas a la hora de describir la traducción.

El narrador y protagonista de "Las dos orillas" es el fraile ecijano Jerónimo de Aguilar, personaje histórico ampliamente documentado, si bien de manera contradictoria (véase infra), que sobrevivió, junto con un compañero andaluz, Gonzalo Guerrero, al naufragio de la expedición de Juan de Valdivia en 1511. Cuando en 1519 Cortés llegó a la isla de Cozumel en la península de Yucatán, se enteró de que en aquellas tierras se encontraban 
varios náufragos españoles que habían sido tomados prisioneros por los mayas. Entonces es, según las crónicas, cuando Aguilar, contrariamente a Guerrero, se sumó a Cortés en la marcha hacia el imperio azteca y desempeñó un relevante papel como traductor en la empresa conquistadora.

En su primer encuentro con el capitán, Jerónimo de Aguilar muerde la cáscara de una naranja para convencer a Cortés de su origen español, exclamando: “Hay imagen que mejor refrende nuestra identidad que un español comiendo una naranja?" (48). Nada más pisar suelo americano, el propio Jerónimo se apresuró a plantar las semillas de un naranjo (46-47). ${ }^{4}$ Son llamativas y hasta sospechosas estas confirmaciones expresas de identidad española en un sujeto que reúne, por lo demás, todos los requisitos del arquetípico cautivo, como si quisiera borrar las huellas inevitablemente dejadas por su encuentro cercano con la otredad americana. Más adelante, veremos que el énfasis puesto en la 'españolidad incontaminada' forma parte de una estrategia del personaje destinada a ocultar su pertenencia a dos patrias y su implicación en la hostilidad maya, que comparte con Guerrero. En la versión de Fuentes, Cortés, sin darse cuenta, había incorporado un traidor a sus filas.

"Las dos orillas" no se presenta como una reconstitución fiel de la historia. Deliberadamente anacrónica e inverosímil, la voz narrativa de Jerónimo de Aguilar nos dirige su monólogo interior desde la tumba en el fondo del lago de Tenochtitlán ${ }^{5}$ donde descansa desde que murió de peste bubónica. En las últimas páginas, revela que el texto que leemos, redactado en español, es fruto de un manuscrito "que al alimón hemos pergeñado dos náufragos españoles" (58), aunque más adelante resulta que la autoría le corresponde a él ya que Gonzalo "está demasiado ocupado combatiendo y conquistando" (59) y quien actúa no tiene tiempo de narrar.

A este monólogo interior han servido de palimpsesto algunos capítulos de la crónica de Bernal Díaz del Castillo, Historia verdadera de la Conquista de la Nueva España, que aparecen mencionados y citados. La reescritura ha surgido a raíz de la frustración de Jerónimo de Aguilar, que no se conforma con lo que de él dijo el famoso cronista: "Cincuenta y ocho veces soy mencionado por el cronista Bernal Díaz del Castillo en Historia verdadera de la Conquista de la Nueva España. Lo último que se sabe de mí es que ya estaba muerto cuando Hernán Cortés, nuestro capitán, salió en su desventurada expedición a Honduras en octubre de 1524. Así lo describe el cronista y pronto se olvida de mî" (12).

Cabe observar la imposibilidad histórica de semejante desacuerdo, ya que la crónica, terminada hacia 1575 , no se publicó hasta muy tarde, en 1632, fecha posterior a la muerte del intérprete. ${ }^{6}$ Aun así, éste, desde su imposible lugar de enunciación, critica al cronista de Medina del Campo "al que sobraba memoria pero faltaba imaginación" (13). Juicio sorprendente, ya que los especialistas en materia de crónicas de Indias hacen notar, por el contrario, que éstas, en general, deben más a la imaginación que a la descripción real de los hechos (Seed 1998; Serna 2000). No olvidemos que la influencia de los poco autorizados libros de caballerías contribuyó a crear un ambiente de realismo mágico en el que se desarrolla la mayoría de las cró- 
nicas (Serna 2000: 66). Es, además, de sobra sabido que, entre los cronistas, Díaz del Castillo es uno de los más directos e inmediatos, por haber participado personalmente en la expedición cortesiana de 1519 (Oviedo 1995: 133). La crítica ha recalcado que la fuerza persuasiva de la obra de Díaz del Castillo reside menos en la veracidad factual que en "la visión popular de la historia y el sabor 'espontáneo' de su prosa” (Oviedo 1995: 135). Aunque hay poco de literario en su crónica, y nada de pretensión erudita, Díaz del Castillo se aleja decididamente del concepto de autoridad e impone sus propios modelos. En el capítulo LXXXVII, por ejemplo, alude explícitamente al Amadís de Gaula, una fuente pocas veces citada por temor a la protesta de moralistas y humanistas (Serna 2000: 66) pero que formaba parte de la literatura popular de tradición oral. Arremete constantemente contra su predecesor Francisco López de Gómara. No sólo quiso rectificar errores de información y de juicio, sino que tampoco toleraba la concepción individualista y aristócrata de este último, que otorgaba todo el mérito de la empresa conquistadora a Cortés. Por su parte, Díaz del Castillo introdujo un planteamiento novedoso cercano al testimonio y vertebrado por la construcción desde abajo de un 'nosotros' de los soldados, a fin de "dar voz a aquellos que hicieron la conquista pero que no fueron narrados" (Añón 2003: 44).

Por todos estos motivos, el propio Carlos Fuentes define a Díaz del Castillo, en su ensayo "La épica vacilante de Bernal Díaz del Castillo" (Valiente mundo nuevo, 1990), como el primer novelista latinoamericano. Al terminar su libro, casi medio siglo después de su llegada a México, el cronista se vio enfrentado a la paradoja de que debía evocar las grandezas de México desde el amor por lo que se había visto obligado a destruir, cuando el mundo azteca ya había desaparecido. Esta condición hace de Díaz del Castillo un hombre escindido, un primer eslabón en la modernidad latinoamericana. Así las cosas, pretender que el cronista carecía de imaginación implica una visión iconoclasta frente al consenso académico y transgresora con respecto a la relación entre lengua y realidad. Tal concepción radical es la que subyace a la reescritura de la crónica llevada a cabo por Jerónimo.

En primer lugar, Jerónimo de Aguilar invierte el orden cronológico de la crónica. Las once secciones de su propio relato se suceden de diez a cero, como si de una cinta rebobinada se tratara, empezando por la conquista de Tenochtitlán en 1521 y remontándose a la llegada de Cortés a Yucatán dos años antes. Partir de diez para llegar a uno no sirve aquí de procedimiento apocalíptico, sino que es una manera de fomentar "un perpetuo reinicio de historias perpetuamente inacabadas" (61), que culmina en la sección cero con la salida utópica de la invasión de Andalucía por los mayas; un desenlace situado fuera del tiempo, que pertenece al reino de lo posible. Esta ficción, puesta en boca de Jerónimo de Aguilar, no es más ficticia que la contenida en las crónicas supuestamente históricas. Se postula aquí la reversibilidad de los hechos, puesto que "siempre pudo ocurrir exactamente lo contrario de lo que la crónica consigna” (14), y los vencidos de hoy pueden ser los vencedores de mañana. 
La voz póstuma de Jerónimo declara que este final se hubiera ajustado mucho mejor al pacto tácito entre él mismo y Gonzalo Guerrero, contrariamente a como queda consignado este episodio en la crónica de Díaz del Castillo. Según la versión 'oficial', ambos supervivientes del naufragio español en tierras mayas reaccionaron de modo muy diferente ante su situación: Jerónimo se fue con Cortés mientras que Gonzalo se negó a partir con sus compatriotas. Tan rotunda fue la negativa de este último que se dedicó a combatir a los españoles comandando partidas de guerreros mayas. Sus hábiles estrategias contribuyeron a que la conquista de Yucatán no se consolidase hasta 1546. Finalmente moriría defendiendo el suelo maya del ataque de las tropas españolas dirigidas por Pedro de Alvarado. Representa así Gonzalo Guerrero un modelo de transculturación opuesto al de otro personaje del relato, la famosísima Malinche (cuyo nombre original era Malinali): la transformación de español en indio, lo que le ha convertido en una figura legendaria todavía presente en la memoria colectiva de los mayas de Yucatán (González Hernández 2002: 242).

Ahora bien, Jerónimo sostiene que la decisión para la contraconquista fue tomada de común acuerdo para que el mundo indio triunfase sobre el europeo (55). A lo largo de todo el episodio descrito, el verdadero traidor hubiera sido entonces Jerónimo (50). Ante la derrota profesional del intérprete, que comentaremos en el apartado siguiente, éste se ve condenado ahora a acompañar como una estrella lejana a Gonzalo, que con lanzallamas mayas conquista Sevilla y edifica "el templo de las cuatro religiones, inscrito con el verbo de Cristo, Mahoma, Abraham y Quetzalcóatl” (55). A la luz del desenlace del relato, cabe subrayar el peso que su autor Carlos Fuentes confiere al concepto de traducción.

Hace tiempo que el texto traducido ha dejado de ser visto como un ente estático o como una simple sustitución de palabras. En nuestra era posmoderna, la traducción se considera más que nunca un agente de producción, y se usa como metáfora de todo acto de conocimiento, con los desplazamientos y las modificaciones que implica. Vista en estos términos, la reescritura de Jerónimo obedece a una lógica translaticia: repite interpretando y, por lo tanto, introduce variantes. Es, además, preciso reconocer la falta de fronteras, la continuidad entre la traducción y el original.

Cuando, por su parte, reescriben los indígenas al imperio, contraeescriben. Si bien las repeticiones textuales de la sección diez en la sección cero subrayan los múltiples paralelismos entre la conquista de México y la contraconquista de Andalucía, implicando ambas operaciones violencia y daños colaterales, salta a la vista una diferencia capital: los mayas deshacen la naturaleza de la conversión religiosa impuesta a España desde los Reyes Católicos y levantan el dogma de la pureza de sangre, que guiaba a la Inquisición, a fin de erradicar la intolerancia reemplazándola por una alabanza del mestizaje, por una restitución de todo lo prohibido y mutilado y por una derogación de los decretos de expulsión de judíos y moriscos. ${ }^{7} \mathrm{El}$ acto maya de traducir la conquista comporta un componente emancipatorio, un potencial subversivo, y su extrañeza resulta liberadora. Por analogía, aun- 
que en un nivel discursivo, la reescritura de Díaz del Castillo por Jerónimo también puede ser considerada, y lo fue de hecho por Paul Jay (1997: 409), una operación de traducción productiva, aliada natural del mestizaje gracias a los elementos transformacionales que le son inherentes. Y si ahora leemos la memoria de Jerónimo en español, la razón es clara. Fruto de aportes sucesivos, la lengua española se ha mantenido flexible y abierta. Una vez liberada del yugo castizo, estaba libre para acoger otras influencias; se le irán imprimiendo, por ejemplo, inflexiones indias. En opinión de Fuentes, no cabe duda de que el gran saldo favorable de la conquista es la lengua. ${ }^{8}$

\section{Una impostura translaticia}

Por el perverso procedimiento narratológico del orden al revés, la reescritura apócrifa de la crónica de Bernal Díaz contenida en "Las dos orillas" parece dictada por propósitos nobles, de solidaridad con la causa indígena. A medida que avanza el texto, el lector descubre, sin embargo, que no es así, y que, antes bien, las memorias de Jerónimo constituyen un ajuste de cuentas por las humillaciones que le fueron infligidas tanto por Cortés como por su rival profesional, la Malinche.

Al principio, Jerónimo estaba ilusionado y decidido a transformar su impotencia de prisionero maya en fuerza expresiva. De ahí que de mero mediador lingüístico que sólo ocupa los bordes - las orillas - del relato en la crónica de Díaz del Castillo pase a protagonizarlo. Rechazando ser relegado a los márgenes, Jerónimo quiere asignarse un papel más heroico, imaginándose que su forma de utilizar las palabras no es exclusivamente instrumental, sino que puede determinar el curso de la conquista de México y contribuirá a generar una nueva realidad.

El conocimiento de las lenguas maya y castellana hace de él momentáneamente la persona con más poder del Nuevo Mundo, "amo provisional de las palabras" (44), hasta la aparición en escena de la Malinche, la segunda 'lengua' del conquistador (lengua tomada aquí en su acepción metonímica de "intérprete' ${ }^{9}$ ). La Malinche, conocida también por los españoles como doña Marina, era una mujer de linaje indígena de excepcional belleza, que le fue obsequiada a Cortés. ${ }^{10}$ Bernal Díaz del Castillo le dedica un capítulo entero de su crónica, el XXXVII, que plantea serios problemas de credibilidad (González Hernández 2002: 199). Sea como sea, la Malinche dominaba el náhuatl y el maya, y Cortés la integra en el triple sistema de traducción de la primera etapa de la conquista: primero Cortés se comunicaba con los mayas a través de la interpretación de Jerónimo de Aguilar y con los aztecas a través del esfuerzo conjunto de éste y Doña Marina, en una situación que hoy llamamos de relay consecutive interpretation. Pero de intérprete, la Malinche alcanzó rápidamente el estatuto de amante, consejera y espía del conquistador. Por medio del uso de la palabra, y gracias a su adhesión a la empresa de los españoles, se transmutó de objeto subalterno en sujeto pleno, dotado de poder. Cuando muy pronto aprende el español, le hace perder a 
Jerónimo su monopolio de esta lengua. Después de la fundación de Veracruz, se produce el drama de Cholula, donde ambos intérpretes se miden.

Es cuando Jerónimo, por primera vez, deja de ser útil, ya que, perplejo, observa que "todo eso lo tradujo del mexicano al español la Malinche" (34). En el episodio del apresamiento del emperador azteca Moctezuma, la Malinche actúa con suma eficacia diplomática y ella ahora es quien se ha vuelto dueña del discurso por haber logrado situarse entre varios sistemas de transmisión. No pocas discrepancias surgen entre los dos intérpretes, resueltas invariablemente a favor de la Malinche, una vez que se convirtió en la intérprete de todos los deseos de Cortés. Como para Jerónimo el control de la lengua equivalía al ejercicio del poder, comprende, amargado, que la "hembra diabólica" (34) le había arrebatado su singularidad profesional.

Pero hay más. La competencia entre Jerónimo y la Malinche no sólo era de orden profesional. Cuando conoce a la Malinche, Jerónimo se enamora de ella e invoca una solidaridad compartida contra los españoles. La Malinche hiere su orgullo y le rechaza: sólo se desnuda ante él para negarse (43). Al día siguiente, Cortés la escoge como su concubina y su lengua. Marina ha apostado por su futuro, llegará a ser la primera cristiana de la Nueva España, madre del primer mestizo.

Entre los tres personajes - Cortés, la Malinche y Jerónimo - se instaura una pugna desiderativa triangular en el sentido que Girard ha asignado al término, que los relaciona mutua e irremediablemente. Jerónimo experimenta una sensación de castración: la competencia se ha vuelto desleal, el combate desigual. Se niega a enseñarle la lengua española a la Malinche. Ya no importa, ésta se la arranca al sexo de Cortés (34). Como siempre, los celos van acompañados de un elemento de fascinación. Aunque Jerónimo termina por compadecer a la Malinche, porque acaba siendo abandonada por el conquistador, con la carga de un hijo sin padre, estigmatizada por su pueblo con el mote de la traición (44), simultáneamente la admira y la comprende: "madre y origen de una nación nueva, que acaso sólo podía nacer y crecer en contra de las cargas del abandono, la bastardía y la traición..." (44). ${ }^{11}$

La intervención exitosa de su rival también fuerza a Jerónimo a modificar la estrategia translaticia. Hasta entonces, su acercamiento moral a los indígenas le había llevado a traducir mintiendo, como un falsario, de acuerdo con el lema "traduje, traicioné, inventé" (18), ${ }^{12}$ encarnando así el fantasma tan temido en el discurso común. No comunicaba a las autoridades indígenas lo que Cortés realmente decía, sino que convertía sus ofrecimientos de paz en declaraciones de guerra. Traducía con imaginación, revelando las verdaderas intenciones del conquistador para tratar de poner en guardia al pueblo con el que simpatizaba porque deseaba una victoria indígena. Éste es el dilema de Jerónimo: no puede dormir en paz porque se pregunta cuál fue su responsabilidad deontológica. Retrospectivamente, se da cuenta de que sus traducciones tergiversadas contenían una verdad profética. Sucedió exactamente lo que él, mentirosamente, previó: se cumplió la comedia cruel que inventó (19). Ahora, corroído por el remordimiento, piensa que sus falsas palabras han provocado la derrota azteca. No debería haber esperado que le 
hiciera caso Moctezuma, cuya cultura de fatalismo contrastaba agudamente con la astucia renacentista de Cortés. ${ }^{13}$ Pero en última instancia, "la culpable fue una mujer" (20), doña Marina, desde cuya aparición en Tabasco Jerónimo deja de gozar de impunidad translaticia. Ella comete una serie de traiciones simétricas pero opuestas a las suyas, ya que favorecen a los españoles.

Un determinado código lingüístico nunca es transferible a otro sin que se produzca una alteración de su significado, pero la Malinche va mucho más allá de esa premisa y hace de la lengua un arma. Maneja la información, revela secretos y debilidades del enemigo, manipula las palabras puestas en sus manos para utilizarlas en la forma que más convenga a sus intereses personales. A esas alturas, la conquista de México parece depender de la lucha entre dos traductores.

Espoleado por la envidia y el odio hacia esa pareja que le ha ninguneado, Jerónimo hace todo lo que puede para que triunfe su táctica de resistencia. Cuando Cortés se entera de que los españoles han sido vencidos en Veracruz, y lleva preso a Moctezuma, los dos intérpretes hablan con lengua bífida y se comportan como agentes dobles. La Malinche explica al conquistador las disensiones entre aztecas y otros pueblos de México, Jerónimo contraataca comunicando a Moctezuma que Cortés también era asediado desde España. ${ }^{14}$ Cuando Moctezuma termina lapidado, Jerónimo tampoco desaprovecha su última oportunidad. Es designado como intérprete en la entevista entre Cortés y Guatemuz (Cuauhtemoc), el último emperador azteca, que tuvo lugar en 1521. De nuevo, traduce a su antojo para impedir la derrota indígena, pero fracasa, y la Malinche tiene la última palabra. Las posibilidades y alternativas de libertad incumplidas le quitan ahora el sueño al intérprete.

\section{Jerónimo de Aguilar: un agente intercultural}

Pero la historia no acaba aquí. La victoria española se reveló en parte pírrica porque Cortés fue considerado en su propio país un sublevado que se arrogó derechos sin autorización del Rey, Carlos Primero de España (Carlos V de Alemania). La conquista fue, a fin de cuentas, una derrota compartida, una épica angustiada.

Cuando Jerónimo ya no puede actuar, se pregunta si no se puede vengar de otra manera, "si un cuento que no es narrado ocurre en realidad" (60). La única certeza que le queda es que en las dos orillas triunfan las palabras. Cuando todo ha terminado, el vacío que surge debe ser llenado de palabras. Carlos Fuentes apuesta por la memoria literaria como espacio utópico que procesa la memoria histórica. Se admite generalmente que se recupera la memoria recuperando la palabra; Fuentes pretende que el mero lenguaje permite plasmar una realidad alternativa.

"Las dos orillas" alegoriza el desencuentro trágico entre dos mundos impenetrables mutuamente, entre dos tipos de civilización: una, renacentis- 
ta, la otra, primitiva y premoderna (Pastor 1988). La mirada mítica de los indios, que no conocían el caballo, transformó a los soldados españoles en centauros. Abundaron las profecías anunciadoras del regreso de Quetzalcóatl o la Serpiente Emplumada, el soberano tlolteca divinizado, de modo que se produjo la confusión fatídica entre los barbados temidos y los conquistadores. Múltiples han sido las hipótesis avanzadas para explicar la actitud de pasividad de Moctezuma. Jerónimo la atribuye al carácter sagrado que revestía la lengua: Moctezuma llevaba el título imperial de Señor de la Gran Voz, el Tlatoani o dueño de la palabra, de ahí que la soberanía del emperador aparezca definitivamente mermada cuando pierde poco a poco el dominio sobre esas mismas palabras que antes le otorgaban prestigio. Los españoles no sólo mataron el poder indio, sino también la magia que lo rodeaba (17). Estas elaboraciones sobrenaturales constituyeron simultáneamente la debilidad y la fuerza del mundo indígena.

Por sus imposturas translaticias, Jerónimo ya había demostrado haber asimilado la cosmovisión precolombina. En el desenlace, actualiza una última y radical posibilidad incumplida criticando la historiografía occidental (representada aquí por la Historia verdadera) e imaginando una contraconquista de España bajo el mando de su antiguo compañero Gonzalo Guerrero, que implica la resurrección indígena. De esta manera, la concepción prehispánica de la palabra, que es mágica y ritual, se convierte en fuente de energía creativa: la fabulación toma el relevo de la historia. Porque si el silencio confirma el orden de las cosas, la narración lo disputa (60).

Menos famoso que la Malinche, Jerónimo es sin embargo el verdadero protagonista del cuento, el único en haber conocido y explorado a fondo 'las dos orillas', la ibérica y la americana. Sintetiza el cúmulo de experiencias paradójicas, la ambigüedad inherente a todo proceso de mestizaje. Cabe subrayar, además, que el fraile parece predestinado a desempeñar el papel de traductor, ya que lleva el nombre mismo del patrón de los traductores, San Jerónimo. Contrariamente a la Malinche y Gonzalo Guerrero, la nativa y el extranjero que, como tránsfugas prototípicos que amenazan el orden social y el sistema de creencias en que descansa, se entregaron en cuerpo y alma al 'otro' enemigo, Jerónimo encarna al sujeto que ocupa la posición intermedia que Fuentes apoya.

El autor se ha aprovechado de una discusión histórica en torno al personaje para desarrollar su propia visión audaz. No hay acuerdo entre los cronistas a la hora de determinar si, en el momento en que los busca Cortés, Jerónimo fue o no a acusar a Gonzalo. Analizada con mayor detenimiento, la diferencia ideológica entre el tránsfuga y el cautivo es coyuntural y gradual antes que esencial. Las dos figuras están íntimamente relacionadas. Además, algunos datos históricos ya sitúan a Jerónimo más allá de la frontera de la renegación. Así, se dice que, más tarde, el casto Jerónimo tuvo dos hijos naturales con una india. Hasta Bernal Díaz del Castillo observa que Jerónimo se aindió (capítulo XXIX) al punto de ser confundido físicamente con los indígenas. El náufrago incluso experimenta dificultades al hablar español: tiene que volver a aprender su idioma materno después de haber 
vivido ocho años entre los mayas. Como ya dijimos, comentando la escena de la naranja, ante Cortés se empeña tanto en dramatizar su condición de cautivo que su súplica resulta sospechosa. ${ }^{15}$

Fuentes da un paso más y le otorga al intérprete el estatuto de traductor-traidor, le dota de una visión bifocal y comenta las tensiones identitarias que tal situación de desarraigo supone. Agente intercultural en mayor medida aún que la Malinche, Jerónimo posee el perfil del mestizo precursor del híbrido poscolonial. No se engaña cuando hace balance: "Nadie salió ileso de estas empresas de descubrimiento y conquista, ni los vencidos, que vivieron la destrucción de su mundo, ni los vencedores, que jamás alcanzaron la satisfacción total de sus ambiciones, antes sufrieron injusticias y desencantos sin fin" (12-13). No se conforma, sin embargo, con un papel servil, sino que reivindica su lugar y con este fin enlaza el Viejo y el Nuevo Mundo, construye un puente entre los vivos y los muertos llevando a cabo una resurrección y un sacrilegio a la vez.

En un nivel más abstracto, "Las dos orillas" desemboca en una reflexión a propósito de la compleja relación entre origen y reproducción. Establece un paralelismo entre lo que ocurría en las Américas en aquella época y lo que le sucedía al intérprete en relación con el texto original; ambos, tanto el subalterno colonizado como el traductor reproductor han sido declarados inferiores. De igual manera, la colonia durante mucho tiempo ha sido considerada como una reproducción, una copia del original que reposa en el Viejo Mundo, condenada a estar siempre subordinada a dicha fuente. De ahí probablemente que según Susan Bassnett (2003: 63), parte de las reflexiones más interesantes sobre la traducción nos llegue de las antiguas colonias. No en vano, algunas de las metáforas más radicales para describir el proceso de traducción proceden de las Américas. Cuestionan abiertamente la premisa "de que la traducción es siempre jerárquicamente inferior al original" (ibid.), impugnan la autoridad que en cierto momento se atribuyó Europa para presentarse como el original último.

En "Las dos orillas", la labor interpretativa de Jerónimo demuestra que, lejos de ser un 'mal necesario', o sea, una transcripción meramente instrumental, la traducción, que consiste en poner algo en el lugar de otra cosa pero en una superposición inestable, puede llegar a constituir una auténtica y performativa herramienta de resistencia y desembocar en una contraconquista. De verse como un mero vehículo a través del cual hace su camino el texto en otras lenguas, al traductor se le reconoce hoy como una figura que toma parte activa o que, por motivos políticos, toma partido.

\section{Bibliografía}

Álvarez, Román (ed.) (2002). Cartografías de la traducción. Del post-estructuralismo al multiculturalismo. Salamanca: Ediciones Almar.

Añón, Valeria (2003). "El cronista y la memoria. Una lectura de la Historia verdadera de la conquista de la Nueva España, de Bernal Díaz del Castillo". Barrenechea (2003), 43-49. 
Barrenechea, Ana María (comp.) (2003). Archivos de la memoria. Rosario: Beatriz Viterbo Editora.

Bassnett, Susan (2002). "La traducción como remembranza". Álvarez (2002), 59-76.

De Toro, Alfonso (2002). "Hybriditäts- und Translationsstrategien für einem neuen (transversalen) historischen Roman". Conferencia en el LateinamerikaInstitut FU Berlin, 23.01.2002. On line en: http://www.uni-leipzig.de/ detoro/sonstiges.fuentes.pdf (consultado 20.12.2004).

Díaz del Castillo, Bernal (1968). Historia verdadera de la conquista de la Nueva España. Madrid: Espasa-Calpe, colección Austral, segunda edición.

Fuentes, Carlos (1990). Valiente mundo nuevo. Épica, utopía y mito en la novela hispanoamericana. Madrid: Mondadori.

Fuentes, Carlos (1991). Ceremonias del alba. Madrid: Mondadori.

Fuentes, Carlos (1992). El espejo enterrado. México: Fondo de Cultura Económica.

Fuentes, Carlos (1993). El naranjo. Madrid: Alfaguara.

Fuentes, Carlos (2000). Los cinco soles de México. Memoria de un milenio. Barcelona: Seix Barral.

González Hernández, Cristina (2002). Doña Marina (La Malinche) y la formación de la identidad mexicana. Madrid: Ediciones Encuentro.

Goytisolo, Juan (1995). El bosque de las letras. Madrid: Alfaguara.

Goytisolo, Juan (2002). España y los españoles. Barcelona: Lumen.

Gruzinski, Serge (1999). La pensée métisse. Paris: Fayard.

Jay, Paul (1997). "Translation, Invention, Resistance: Rewriting the Conquest in Carlos Fuentes's 'The two shores"'. Modern Fiction Studies 43(2), 405-431.

Lie, Nadia \& Theo D'Haen (eds) (2002). Zorro \& Co. Populaire personages en het koloniale verleden. Nijmegen: Vantilt.

Oviedo, José Miguel (1995). Historia de la literatura hispanoamericana. I. De los orígenes a la emancipación. Madrid: Alianza.

Pastor, Beatriz (1988 [1983]). Discursos narrativos de la conquista: mitificación y emergencia. Hanover, USA: Ediciones del norte.

Perilli, Carmen (2003). "Mestizaje y arielismo en la escritura de Carlos Fuentes". Espéculo 29.03.2003. On line en: http://www.ucm.es/info/especulo/numero23/mestizaj.html (consultado 20.12.2004).

Seed, Patricia (1998). Ceremonies of Possession in Europe's Conquest of the New World, 1492-1640. Cambridge: Cambridge UP.

Serna, Mercedes (ed.) (2000). Crónicas de Indias. Antología (Letras Hispánicas 483). Madrid: Cátedra.

Van Delden, Maarten (2002). "La Malinche, minnares van Cortés". Lie \& D'Haen (2002), 37-58.

Williams, Raymond L. (2002). "Fuentes the Modern: Fuentes the Postmodern". Hispania 85(2), 209-218.

${ }^{1}$ Ha sido recogida posteriormente en la antología Los cinco soles de México (Fuentes 2000) bajo la rúbrica "La Conquista española". Todas las páginas mencionadas entre paréntesis remiten a la edición de 1993.

2 Los cinco relatos contienen elementos apócrifos y una serie de rasgos tipificados por Alfonso de Toro (2002) como representativos de la metaficción historiográfica.

${ }_{3}$ Gira en torno al naranjo, un ejemplo elocuente del mestizaje en marcha. A pesar de la complejidad aparente del cuento, cede por momentos al simbolismo fácil y descansa en una definición esencialista del mestizaje, que contrasta con visiones dinámicas (Gruzinski 1999). El pensamiento de Fuentes conserva una estructura binaria que reclama su pertenencia a la tradición hegemónica del pensamiento occidental. 
${ }^{4}$ Esta escena ritual se repite en cada uno de los cinco relatos. Así, en el segundo relato, "Los hijos del conquistador", se menciona que a Cortés, al llegar a Yucatán, lo deslumbró ver un naranjo cuyas semillas trajeron hasta allí los dos náufragos desleales, Aguilar y Guerrero (79); cuando desembarcó en Acapulco, sembró un naranjo (113-114) y cuando muere en Andalucía, su único consuelo consiste en el aroma del naranjo en flor en territorio ibérico, gemelo del árbol americano (ibid.).

5 Esta información entra en conflicto con otros indicios. Jerónimo parece circular con facilidad de un mundo a otro porque en otras ocasiones aparece agonizando. La voz narrativa no se mantiene por tanto ni constante ni fidedigna.

${ }^{6}$ Este desfase entre los acontecimientos y el momento de la redacción de la crónica debilita considerablemente la fidelidad histórica del comentario de Díaz del Castillo. 7 No es casual que "Las dos orillas" vaya dedicado al escritor español Juan Goytisolo, cuyo proyecto ideológico de una España de convivencia étnica porosa, y contrario a la dogmática que triunfó de hecho resulta aquí extendido porque incluye, además, a los indígenas americanos. Goytisolo se ha proclamado una y otra vez (por ejemplo en España y los españoles, 2002) en deuda con la teoría de las tres castas de Américo Castro. Léase el artículo de Goytisolo "Las dos orillas de Carlos Fuentes" (Goytisolo, El bosque de las letras, 1995: 71-84) y compare con la empresa de su personaje Don Julián, que condena igualmente el exclusivismo etnocida y el credo católico echando mano de la traición.

8 En su historia El espejo enterrado (1992), que junto con los ensayos de Valiente mundo nиevo entrega las claves de los relatos de El naranjo, Fuentes expone su visión sobre la conquista. Considera fundamental la relación entre América y España como dos culturas en espejo: el debate de América Latina consigo misma es, para Fuentes, un debate con España. Atenúa el papel del colonialismo y plantea el enfrentamiento cultural Norte/Sur. Carmen Perilli (2003) ha analizado este fuerte predominio de la cultura española en el hispanoamericanismo de Fuentes, y llega a la conclusión de que retoma la tesis arielista del espíritu latino por oposición a la barbarie utilitaria sajona. A esta vertiente une, según la crítica, elementos de la tradición indigenista, y proyecta el modelo explicativo del mestizaje a la historia española, lo que le permite tender un puente entre culturas hispánicas.

9 Hasta tal punto aparecen como intercambiables Cortés y la Malinche que el emperador azteca Moctezuma (Montezuma) llega a confundirlos. Prueba de ello es esta cita del capítulo CXXVII de la crónica de Díaz del Castillo: "Y cuando al gran Montezuma se lo fueron a decir de parte de Cortés, dicen que dijo con gran dolor: ¿QQué quiere ya de mí Malinche, que yo no deseo vivir ni oille, pues en tal estado por su causa mi ventura me ha traído?"” (270-271).

${ }^{10}$ Del relativismo de su posición es símbolo la imagen ambivalente con la que es conocida en la historia: mitificada como heroína del amor por los españoles, para los americanos encarnaba la traición por haber entregado su tierra, su gente y su lengua a Cortés. Cristina González Hernández (2002) explica que la imagen de la Malinche no tiene más de dos siglos y medio de existencia simbólica, y que sólo desde el surgimiento de la nación mexicana independiente cristalizó su leyenda. Comenta también interpretaciones y rehabilitaciones posmodernas femeninas y chicanas (véase también Van Delden 2002).

${ }^{11}$ Si bien es cierto que la Malinche inauguró un nuevo discurso, el mestizo, en su función mediadora entre el mundo indígena y el español, el papel de iniciadora del mestizaje biológico pertenece exclusivamente al ámbito de lo simbólico, no de lo histórico, ya que Gonzalo Guerrero, por no ir más lejos, ya había tenido varios hijos de su matrimonio con una india maya antes de la llegada de Cortés.

${ }^{12}$ Lema que recuerda por antítesis al de la futura Real Academia de la Lengua: "limpia, fija y da esplendor". 
${ }^{13}$ En el prólogo a Ceremonias del alba (versión reelaborada de 1991 del drama épico Todos los gatos son pardos), Fuentes alude a 'las dos orillas' del poder. Opone la fatalidad de Moctezuma a la voluntad de Cortés, y Marina hace oficio de puente: "Con sus palabras convierte la historia de ambos poderes en destino: el conocimiento del que es imposible sustraerse" (1991: 9).

14 "Le di al Rey el secreto de la debilidad de Cortés, como doña Marina le había dado a Cortés el secreto de la debilidad azteca: la división, la discordia, la envidia, la pugna entre hermanos, que lo mismo afectaba a España que a México: una mitad del país perpetuamente muriéndose de la otra mitad" (28).

${ }^{15}$ En el capítulo CLXXIV de su crónica, Bernal Díaz del Castillo dice que Aguilar había muerto cuando Cortés emprendió su expedición a las Hibueras. Pero según otras fuentes, el antiguo intérprete aparecerá cuatro años después a declarar contra Cortés en el juicio de residencia al que éste fue sometido. 